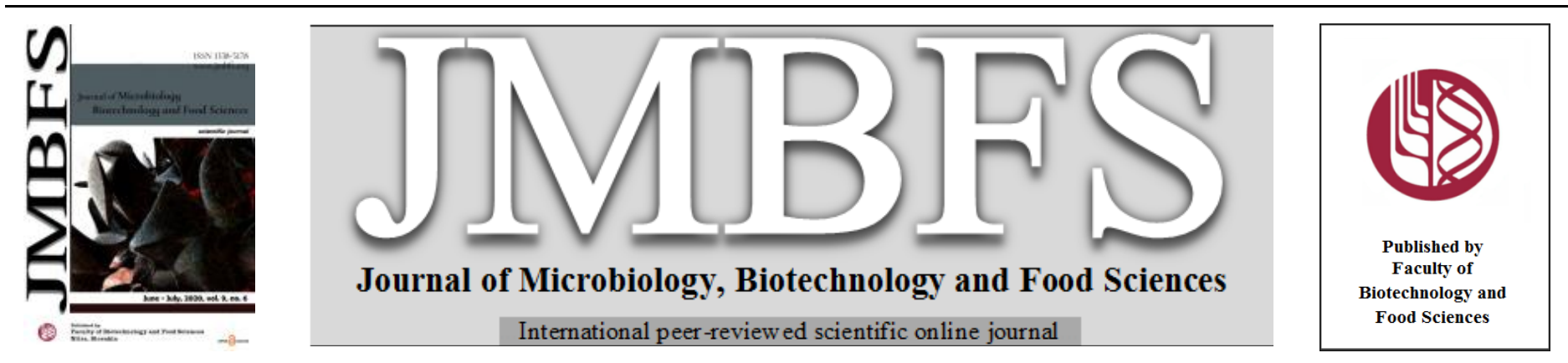

\title{
OPTICAL NANOFIBER AS A SMART DETECTOR OF MYCOTOXINS IN BLOOD
}

\section{Preetha Bhadra ${ }^{1,2}$, Chitrangada Das Mukhopadhaya ${ }^{3}$,Debalina Bhattacharya ${ }^{4}$, Sampad Mukherjee ${ }^{1 *}$}

Address(es): Dr. Sampad Mukherjee,

${ }^{1}$ Department of Physics, Indian Institute of Engineering Science and Technology, Shibpur, 711103, India.

${ }^{2}$ Department of Biotechnology, Centurion University of Technology and Management, Parlakhemundi, Orissa, 761211, India.

${ }^{3}$ Centre for Healthcare Science and Technology, Indian Institute of Engineering Science and Technology, Shibpur, 711103, India.

${ }^{4}$ Cell Biology and Nanobiotechnology Laboratory Life Science and Biotechnology Department Jadavpur University Kolkata-70003.

*Corresponding author: smukherjee.besu@ gmail.com

doi: 10.15414/jmbfs.2020.9.6.1039-1046

ARTICLE INFO

Received 13. 11. 2018

Revised 10. 1. 2020

Accepted 10. 1. 2020

Published 1. 6. 2020

Regular article

open $O$ access

\begin{abstract}
The objective of this study is to use the optical fiber, an emerging device due to their biocompatibility, photo-sensitivity, as a biosensor which can detect the mycotoxin produced by the Aspergillus sp. found in food and feed product of animals. First, we have treated the Red Blood Corpuscles (RBCs) of human blood with different concentration of Aflatoxin B1 and Aflatoxin G1 (AflB1 and AflG1respectively) and after certain time slot, we have studied the changes of the RBC and its protein by Circular Dichorism spectroscopy (CD)and, Fluorescent Spectroscopy. From these Spectroscopic data, it has been found that there was a change in the structure of the Haemoglobin $(\mathrm{Hb})$, supported by theReactive Oxygen Species (ROS), which gives the apoptotic dimension of the RBC. These experiments followed by the preparation of the nanoprobe by etching optical nanofibre with Hydrofluoric Acid (HF) upto certain extent. The prepared nanoprobe was then used to detect theAflB1and AflG1treated RBC.The outcome of the experiments it has been found that the optical nanofiber can detect a small variation of $\mathrm{pH}$ of the solution.
\end{abstract}

Keywords: Aflatoxin B1, Red Blood Corpuscles, Optical Nanofiber, Fluorescent Spectrophotometer, Fourier-transform infrared spectroscopy, Reactive Oxygen Species, Circular Dichorism

\section{INTRODUCTION}

Biosensors are those which can be capable of sensing the biological (cells, Blood, serum etc.), biochemical changes in the cells, Deoxy-ribo Nucleic Acid (DNA), and proteins. These biosensors may be a chemical device (like different solution) (Bing et al., 2013; Bing et al., 2011; Kamrul et al., 2011; Peveler and Algar, 2018) an optical device (like different light wave and fibers) (Wang, T. et.al) or a mechanical device (Kausal et al., 2013; Nayak et al., 2013) Optical nanofiber has found to be the most emerging biosensor (Zhang et al., 2011) which has found to be cost-effective and also a good sensor for the biological species such as protein marker of cells, DNA (Pollock et al., 1995). The development and improvement of optical biosensors are driven by the continuous demand for simple, rapid, sensitive, and in-situ monitoring techniques compared to the costly immunological assay (Leunga et al., 2007). These processes of detection are to be used in a broad range of areas including medical, pharmaceutical, environmental, defense, bio processing, and food industries which include the food and the feed products (Leunga et al., 2007; Wolfbeis et al., 2008). Optical fiber biosensors use the fibers as the transduction element, and rely completely on optical transduction mechanisms for detecting targeted bio molecules (Khijwania et al., 1999; Littlejohn et al., 1999; Bures et al., 1999) by the parameter of changes in $\mathrm{pH}$ of the solution or maybe the antigen binding receptor molecules. One reliable and sensitive optical method is evanescent sensing. These fibers are mostly the single mode fiber (Tong et al., 2004; Lou et al., 2005) which are then tapered to get the ultimate width of the necessity. The tapered fiber follows the wave guideline and this particular phenomenon has led them to have the highest sensitivity and selectivity, fast response, low detection limits (Tong et al., 2003) with a very smaller and thinner in size. As per our review is concerned the optical fiber has got the selective size of the range between $100 \mu \mathrm{m}$ to $1 \mathrm{~mm}$ (Bhatia 1996; Kersey et al., 1997; Bhatia And Vengsarkar 1999; Stephen And Ralph, 2003).

Biologically the detection of the fungi was made visually but the mycotoxins produced by the fungi changes the chemical and the physical composition of the food and the feed product and that has found to be the fatal cause of death these days (Abdulkadar et al., 2004). As per our review is concerned Aflatoxins, produced by the toxigenicstrains of A. Flavusand, A. parasiticus has found to be the most dangerous mycotoxins due to their range of toxicity. On the basis of their toxicity, AflB1 and AflG1 are categorized as most hazardous and fatal among the pool of other Aflatoxins such as B2, G2, M1, M2 (Cast, 1989; Smith et al., 1991). A fluorescent property has also been noticed in these mycotoxins The AflB1 produce blue fluorescence whiles the AflG1 produce green fluorescence and moreover they are more reactive as they all have two difuran rings with oxygen (Acar, 1998). They all may have a selective effect on various cell membranes or target organs where they interfere with the synthesis of themacromolecule and the functions of the organs. This can influence the immunological functions directly or indirectly. Some of these mycotoxins have found to be aneurotoxic or causeotherorgan pathology, and these compounds alsomay activate the endocrine mechanisms, such asthe stress-induced release of corticosteroids inhibits immune function (Sharma et al., 1985; Sharma et al. 1993). Aflatoxins are found as the potent liver toxins, and the effects in animals vary with theamount of the dose, length of exposure of the mycotoxin, species,breed, and diet or nutritional status. In animals, acute aflatoxicosis has been found and the signs and symptoms consist of reduced feed consumption, drastic drops in milkproduction, abnormal weight loss, and acute liver damage (Bodine et al., 1983; Charoenpornsook et al., 2006).

Because mycotoxins are resistant to high temperatures and chemicals, they can be accumulated in grains and heavily contaminate grain-based food and feed that may result in the ill detection of these toxins (Gendloff et al., 1986). There have been radical developments, incremental developments, and techniques for the detection of mycotoxins nowadays (Maragos, 2004). More recently, the changes occurred by the mycotoxins are detected by the image analysis, machine vision systems, and infrared spectroscopy (Pearson 1996; Hirano et al., 1998; Ruan et al., 1998; Dowell et al., 1999; Pearson et al., 2001; Garden et al., 2001; Dowell et al., 2002; Lohninger et al., 2002). Testing for mycotoxins is conducted under many different circumstances and for a variety of reasons and selection of the appropriate method depends upon the usefulness of the method Chromatography, HPLC, ELISA were the most common method used in past days and were not very user-friendly and cost-effective (Sydenham et al., 1997; Bhattacharya et al., 1999; Shephard et al., 2001; Trucksess et al., 2001; Koe et al., 2004). Deciding factors of a method selection may vary between the accuracy andspeed of the method, the skill level required to perform the assay, 
and the cost-effectiveness (Maragos et al., 2004). The opticalfiber has already been used in case of sensing the mycotoxins (Maragos, 1997; Maragos and Thomson, 1999; Jeon et al., 2013) but those have been used by the antibody coating which is a very costly affair to detect the same in all cases and in a huge quantity.

Our aim is to use the Optical fiber in the range of nano $\left(10^{-9} \mathrm{~cm}\right)$ where it is capable of sensing a very nominal change in the $\mathrm{pH}$ of a solution due to its dangle bonds. Using the properties of light and the $\mathrm{pH}$, the detection of the AflB1 and AflG1 has been done in our work.

\section{MATERIAL AND METHODS}

\section{Materials}

The chemicals PBS buffer, $\mathrm{NaCl}, 1 \%$ Methanol as a solvent,AflB1, and AflG1 from Sigma -Aldrich. Distilled water and isolated the RBC with the standard Protocol (Hanson et al., 2008).

\section{Red blood corpuscles isolation}

The $5 \mathrm{ml}$ peripheral venous blood sampled on $\mathrm{Na}_{2}$ EDTA (Sodium Ethylenediaminetetraacetic acid) as anticoagulant and centrifuge (Eppendorf) at 500xg for $10 \mathrm{~min}$ at 4 degrees. Aspirate supernatant (plasma) and add Phosphate Buffer Solution to erythrocyte pellet cells from the top layer containing White Blood Corpuscleswas removed. Centrifuge erythrocytes at 500xg for $10 \mathrm{~min}$ at 4 degrees C. this has repeated for two more times for a total of 3 washes of the blood and collect the RBC pellet. In all of the experiments, we have used RBC preparations with less than $1 \%$ other blood cells.

\section{AFLB1 AND AFLG1 solution preparation}

A stock solution of $20 \mu \mathrm{M}$ as shown in Table 1, concentrations was prepared by dissolving 5mg of AflB1 and AflG1 in $8 \mathrm{ml} \mathrm{1 \%} \mathrm{Methanol} \mathrm{(Sonmez} \mathrm{et} \mathrm{al.,} \mathrm{2013).}$

Table 1 Making of different concentration of the working solution

\begin{tabular}{lcc}
\hline Concentrations & $\begin{array}{c}\text { The volume of the } \\
\mathbf{2 0} \boldsymbol{\mu M} \text { stock }\end{array}$ & $\begin{array}{c}\text { Volume of } \\
\text { Methanol }\end{array}$ \\
\hline $\mathbf{1 0} \boldsymbol{\mu M}$ & $2.5 \mathrm{ml}$ & $2.5 \mathrm{ml}$ \\
$\mathbf{5} \boldsymbol{\mu M}$ & $1.25 \mathrm{ml}$ & $3.75 \mathrm{ml}$ \\
$\mathbf{2 . 5} \boldsymbol{\mu M}$ & $0.625 \mathrm{ml}$ & $4.375 \mathrm{ml}$ \\
\hline
\end{tabular}

\section{Preparation of optical nano fibre}

Length of $1 \mathrm{~m}$ of single mode optical fiber is taken and etched with the HF for 57 mins to obtain the nano range of the fiber.

\section{Methodology}

\section{Treatment of RBC with AFLB1 AND AFLG1}

Isolated RBCs are treated with different concentration of AflB1 and AflG1 and incubated at $37^{\circ} \mathrm{C}$ for different time frame like 3 hours, 6hours, and 12 hours in a $\mathrm{CO}_{2}$ incubator.

\section{Scanning Electron Microscopy}

A field emission scanning electron microscopy (FE-SEM) study was performed to characterize and determine the morphology of the treated RBCs and to find the dimension of theOptical nanofiber. A thin layered RBC sample was coated with a carbon under high vacuum and examined by FE-SEM (Carl Zeiss Supra SEM instrument). Detection of the size of the etched optical fiber has also determined by SEM.

\section{Fluorescence Anisotropy}

The fluorescence anisotropy of PBMC was assessed by the determination of TMA-DPH steady-state fluorescence polarization after the cell membrane exterior phospholipid layer permeation of the probe (Katona et al., 2004; Lakowicz et al., 2004; Shrivastava et al., 2007).

For the measurement of the changes in the TMA-DPH fluorescent properties following the membrane permeation, we added $2.5 \mu$ MTMA-DPHto a $2 \mathrm{ml}$ of RBC suspension an aliquot of TMA-DPH stock solution in DMSO to get $2.5 \mu \mathrm{M}$ TMA-DPH in the measuring cuvette.The cell suspension with the fluorescent probe was incubated for 30 minutes at $37^{\circ} \mathrm{CThe}$ measurement has been done between excitation and emission state, $360 \mathrm{~nm}$ and $430 \mathrm{~nm}$ respectively (on an average of three).

\section{Fourier-Transform Infrared Spectroscopy}

The Fourier-transform infrared spectroscopy has done (triplicate) to analyze the bond between the Hb and the mycotoxins. FTIR (Jasco)of the RBC has done with the preparation of the $\mathrm{KBr}$ (Potassium Bromide) palate on which the $\mathrm{RBC}$ solution was added. $\mathrm{KBr}$ (Potassium Bromide) has been used because of its absorption of excess water from the solution.

\section{Circular Dichorism Spectroscopy}

CD spectra (Jasco-J814) of hemoglobin and hemoglobin treated with differen concentrations of AflB1 and AflG1 were taken after incubation for adifferen hour and centrifuged at4032 g $(6000 \mathrm{rpm})$ for 5 mins. Scan speed $50 \mathrm{~nm} / \mathrm{min}$; bandwidth $1 \mathrm{~nm}$; spectral response $0.2 \mathrm{~nm}$; (taken on an average of three).

\section{Reactive Oxygen Species Analysis}

Membrane fluidity of blood cells was shown to have a decisive role in the direct cell to cell contact and the modulation of the activity of membrane enzymes and to be affected by the increased release of ROS (Hollan, 1996).

For the measurement of the changes in the reactive oxygen of cells, DCF-DA was added to a $2 \mathrm{ml}$ of RBC suspensions. The cell suspension with DCF-DA was incubated for 30 minutes at $37^{\circ} \mathrm{C}$. The measurement was done at $540 \mathrm{~nm}$ on an average of three.

\section{RESULTS AND DISCUSSION}

\section{Scanning Electron Microscopy}

After etching by the HF for 55 minutes, the dimension of the fiberhas been measured by the SEM and shown in the Fig:1. Dimension of the fiber has found to be the order of $50 \mathrm{~nm}$. We have performed the experiment by using the property of propagation of light through the fiber as the etching process is going on. We found that the intensity of the light at the power meter connected in the receiving end of the fiber falls to zero suddenly. This phenomenon is being observed as the dimension of fiber has etched to the dimension of the wavelength of the light and due to this the area of the nano dimension of the fiber creates an evanescent field. The plot shows in Fig 2 the power received by the power meter gradually decreased with the time of etching and after 55-57 minutes the power has falls to zero as there were no light passed though the nano dimensioned fiber.

In Fig 3 (a), (b), (c), (d) the SEM of normal RBC and the treated RBC has shown. The results have taken after $6 \mathrm{hrs}$ of incubation with the drug as the changes have found in the other experiments mostly in that time frame and the changes of the structure of AflB1 to the AflG1 occurs durion that period of time. These results of SEM have shown that the drugs have broken down the membrane of RBC and entered into it. This leads us to do the fluorescence anisotropy and the CD spectroscopy.

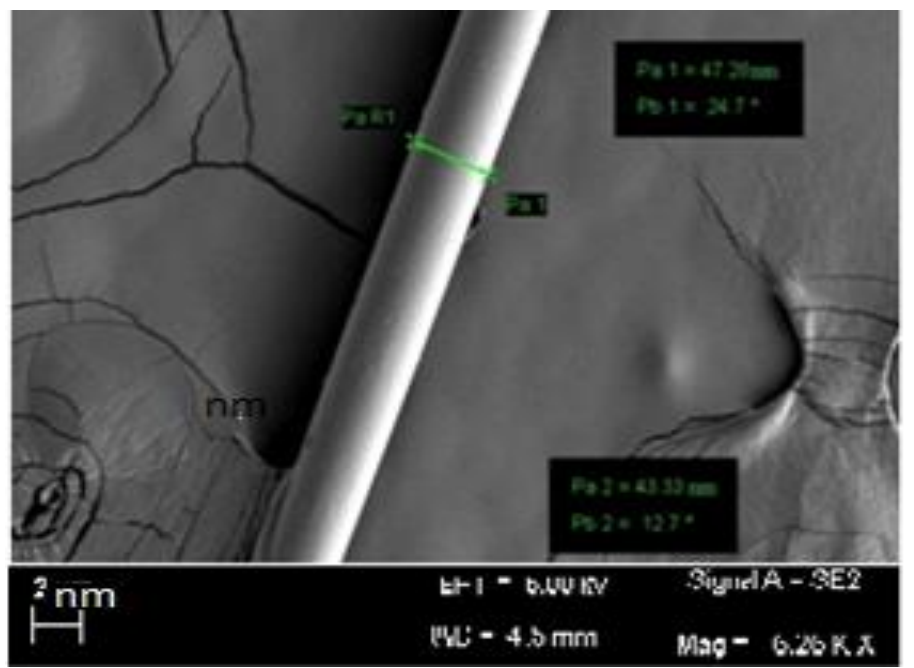

Figure 1 SEM of Optical Nanofiber 

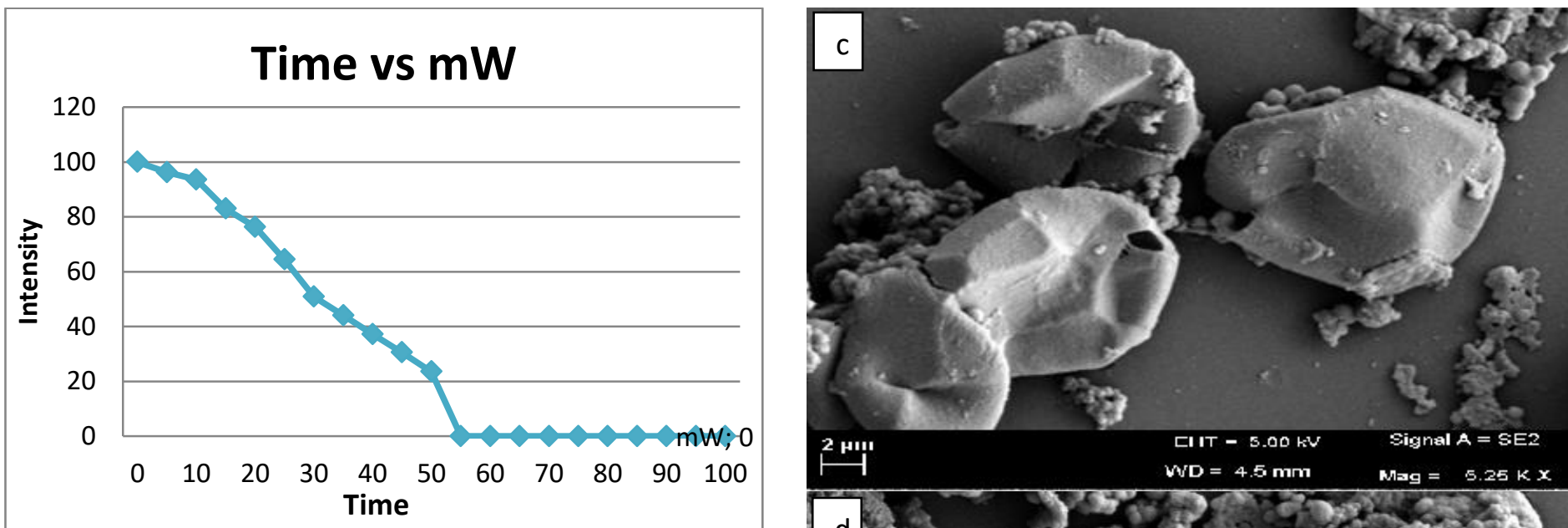

Figure 2Time vs $\mathrm{mW}$ plot
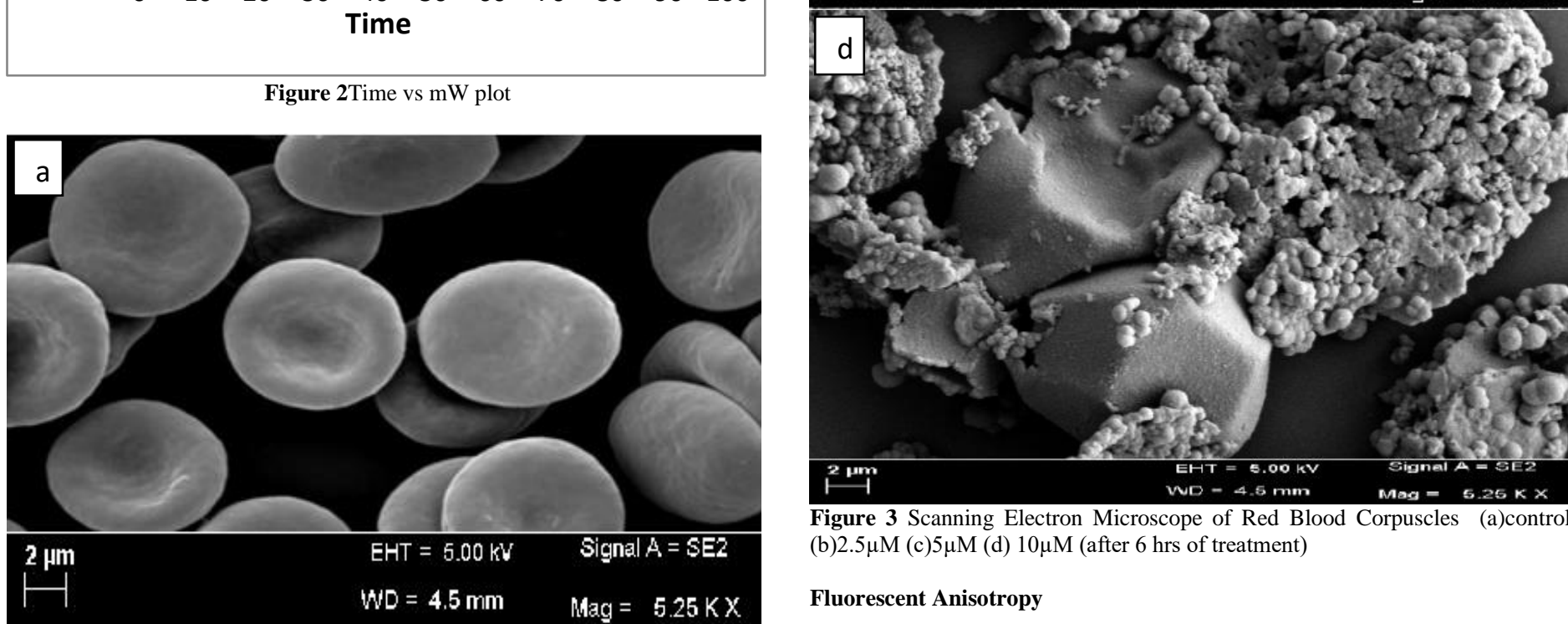

Figure 3 Scanning Electron Microscope of Red Blood Corpuscles (a)contro (b) $2.5 \mu \mathrm{M}(\mathrm{c}) 5 \mu \mathrm{M}$ (d) $10 \mu \mathrm{M}$ (after 6 hrs of treatment)

\section{Fluorescent Anisotropy}

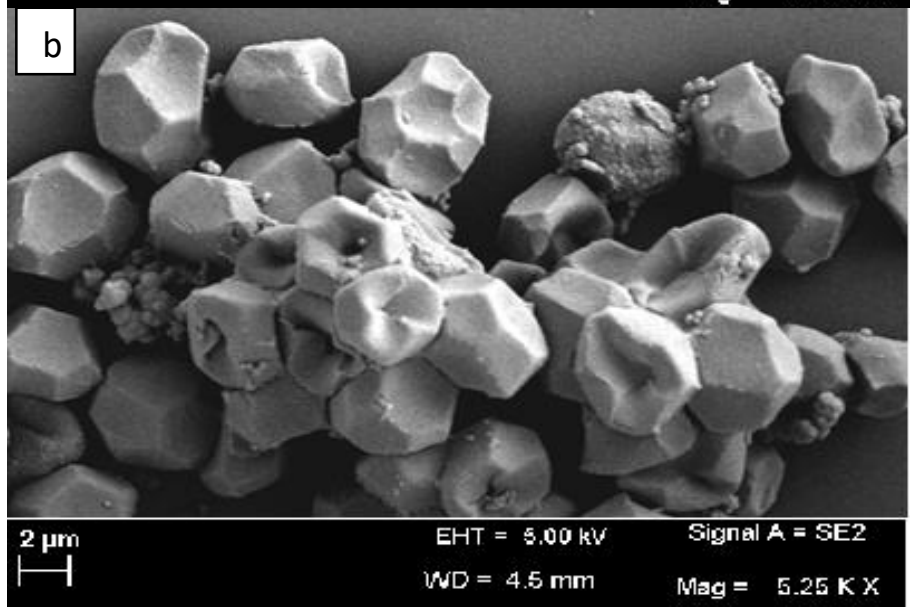

The fluorescence spectra have been studied for all the samples (triplicate) and shown in the Fig:4 The decreasing value of the fluorescence anisotropy leads to the conclusion about the interaction between the $\mathrm{Hb}$ and the AflG1 got minimal due to the lower concentration and not any significant changes are noticed with the increment of the exposure time of this mycotoxin. But on the other hand, the changes in structure of $\mathrm{Hb}$ due to the addition of AflB1 is similar as in the samples treated with AflG1 in a particular time frame which implies that the conformational change ofAflB1 to AflG1 occurs and revives. This is also a confirmatory test that the AflB1 and the AflG1 have shown significant changes in the structure of $\mathrm{Hb}$ and as the values are decreased, the changes in the structural configuration of AflB1 and AflG1 changes to the minimal energy state. The changes of the structure of $\mathrm{Hb}$ have studied further by the $\mathrm{CD}$ spectroscopy. This fluorescent anisotropy is also a confirmatory test that the drug interacts only with the $\mathrm{Hb}$ and not with the membrane proteins present on the surface of the $\mathrm{RBC}$ as the intensity 


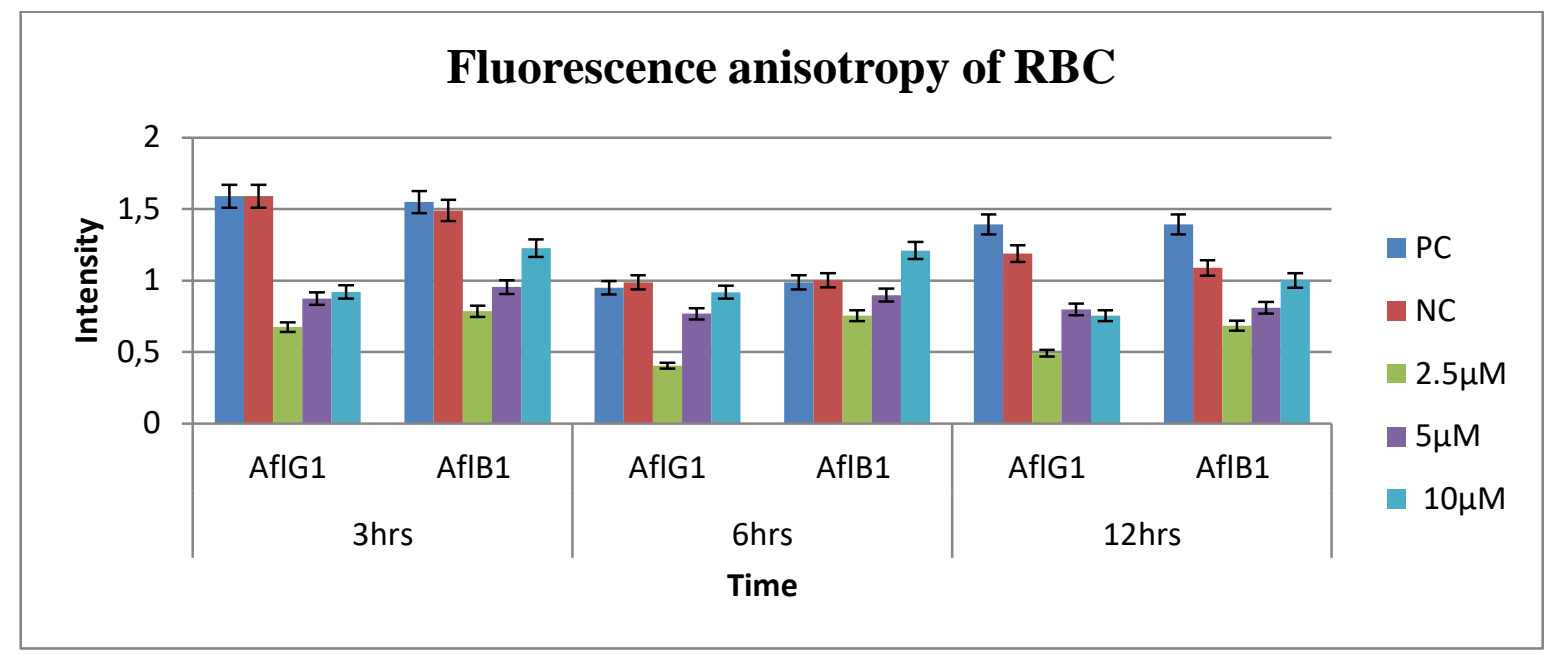

Figure 4 Fluorescence anisotropy of Red Blood Corpuscles with the treatment with AflG1 and AflB1

\section{Reactive Oxygen Species Analysis}

The ROS analysis isthe cell viability test based on the presence of mitochondria. The ROS binds to the mitochondria of a viable cell and changes the density accordingly. The triplicate analysis report of ROS in Fig:4 has clearly shown that the changes of number of RBCs are due to the changes of the structura deformation of $\mathrm{Hb}$ with the interaction of the mycotoxins and it has gradually decreased by the increment of the time of interaction and also with the increment of the concentration of the mycotoxins.It has also be found that there is a similarity with the results after $6 \mathrm{hrs}$ of incubation with the mycotoxins which indicates the structural changes of AflB1 to AflG1.

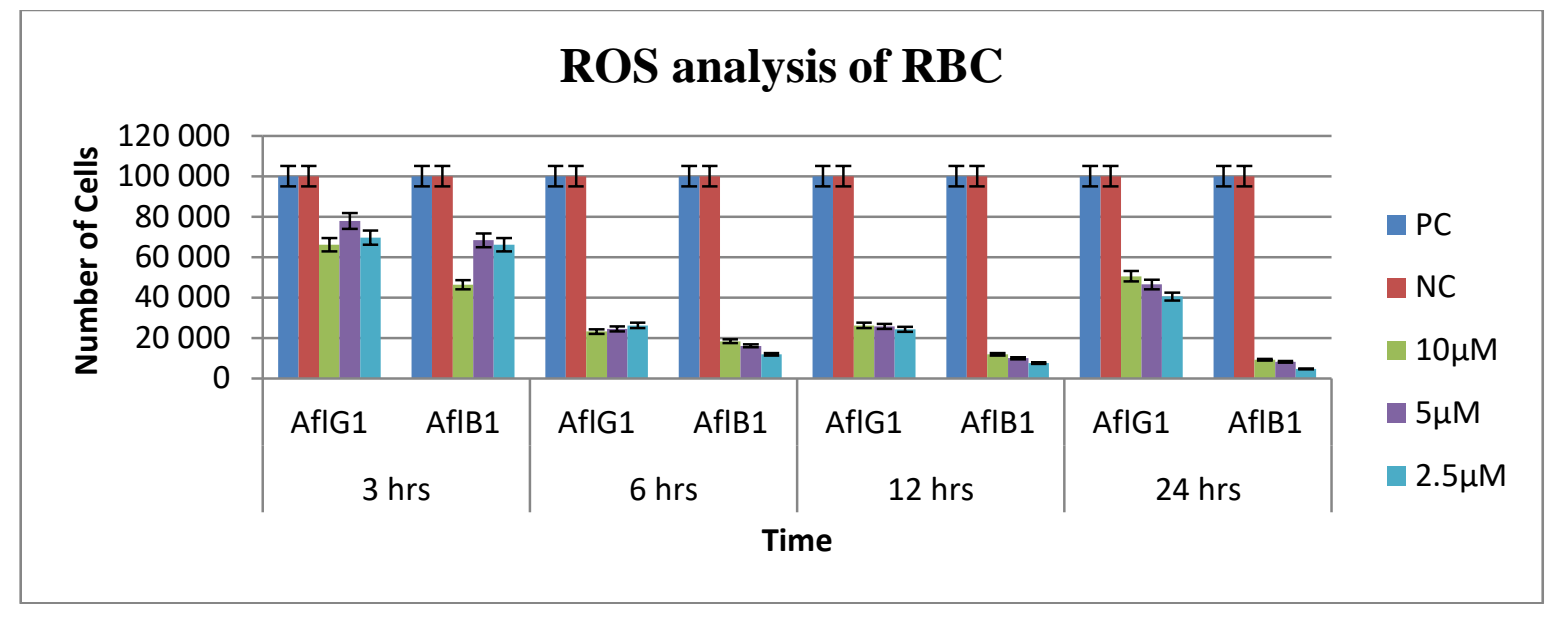

Figure 5 Reactive Oxygen Species analysis of Red Blood Corpuscles with the treatment with AflG1 and AflB1 (cell number (+/-) 1000)

Fourier-Transform Infrared Spectroscopy Analysis

The unconventional peak has found along with the suppression of characteristics peaks of AflB1 in those samples which are incubated for 6 hours for the concentrations of $10 \mu \mathrm{M}$ and $5 \mu \mathrm{M}$ both and these peaks are surprisingly disappeared at 24 hours of incubation. But in the case of $2.5 \mu \mathrm{M}$, the coexistence of unconventional peaks and characteristics peaks of AflB1 occur for different times of incubation of the study. From these results, it can be concluded that the free radical of the $\mathrm{Hb}$ has changed the structure of the AflB1 and again after acertain time the structure revived. So far the molecular structure of different forms of Aflatoxins, the conclusions have been made that the unconventional peaks are due to the formation of AflG1 from AflB1 and as the review is concerned (Mirghania et al., 2001) the scale of toxicity of AflB1 is more than that of AflG1 and this is a good achievement of this work so far reported. One more important findings of this study is that the change in internal energy (preferably known as collision energy) of the structure of AflB1 to AflG1 calculated based on the peaks found in our FTIR data isfairly in agreement with the data reported by ref 47 who are estimated the collision energy value from another experiment like mass spectrographs etc. 

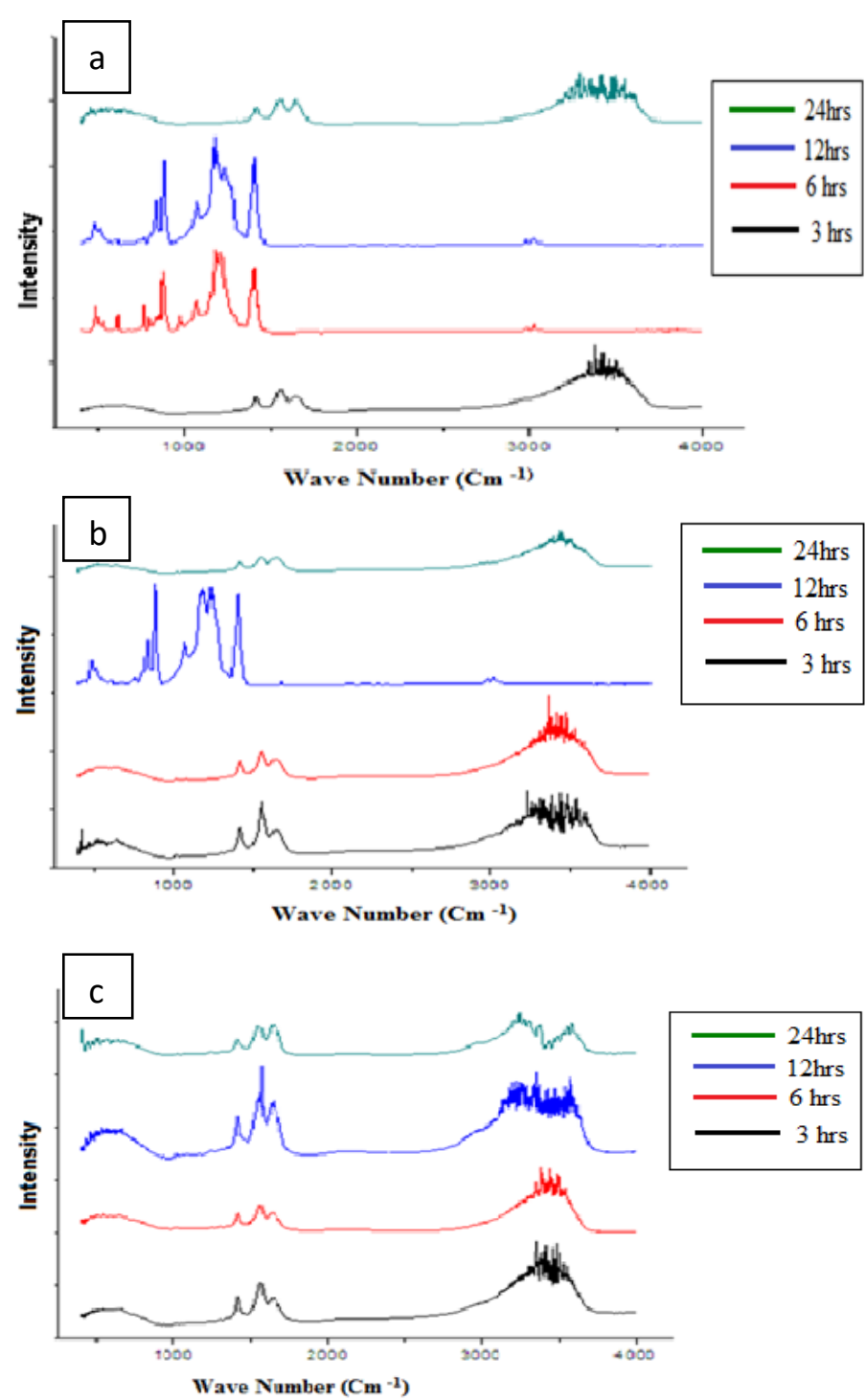

Fig 6 FTIR results of Treated RBC with different concentration of AflB1 (a) $10 \mu \mathrm{M}$ (b) $5 \mu \mathrm{M}$ (c) $2.5 \mu \mathrm{M}$ ( The graphs is showing the changes in the structure of RBC due to the treatment of AflB1 and AflG1)

\section{Circular Dichorism Spectrophotometer}

The interaction of $\mathrm{Hb}$ and the mycotoxins have studied by the $\mathrm{CD}$ spectroscopy. The peak of hemoglobinhas shifted with the change in time of interaction and the concentration of mycotoxins. From our previous finding (Bhadra et al., 2017), from the FTIR analysis, we foundthat AflB1 has changed its conformation to AflG1 and after acertain period of time it regains its previous structure. The presence of $\mathrm{Fe}$ ion in the haemoglobin made easier for a molecule to change its molecular configuration as the $\mathrm{Fe}$ molecule has both the state of +3 and +2 state and as all the molecule wants to stay in its nominal energy state, the AflB1 undergoes the oxidation as it has a $\mathrm{CH}-\mathrm{N}$ in its arm and changes its configuration to AflG1. After acertain period of time, it again releases its energy and comes back to the normal state of AflB1.CD Spectroscopic data havealso shown (Fig:6 (a,b,c,d,e) ) that there is a significant changes in the structure of $\mathrm{Hb}$ due to the interaction with AflB1 which have a similarity to the changes due to AflG1 after 6 hour of incubation, which implies that the mycotoxins interact with the $\mathrm{Hb}$ only, not the other membrane proteins present in the RBCs as the normal CD spectra of $\mathrm{Hb}$ has maintained a regular structure throughout the reaction and also shown that the effect of toxicity of the AflB1 is higher than the AflG1 as we get the change in spectroscopy of the Hb with AflB1 and the AflG1. The shifting of the peaks from the negative to the positive region signifies that the interaction between the $\mathrm{Hb}$ and the AflB1 and AflG1 configure a new protein structure and that leads to a change in the structure and as well as in the morphology of RBCs.

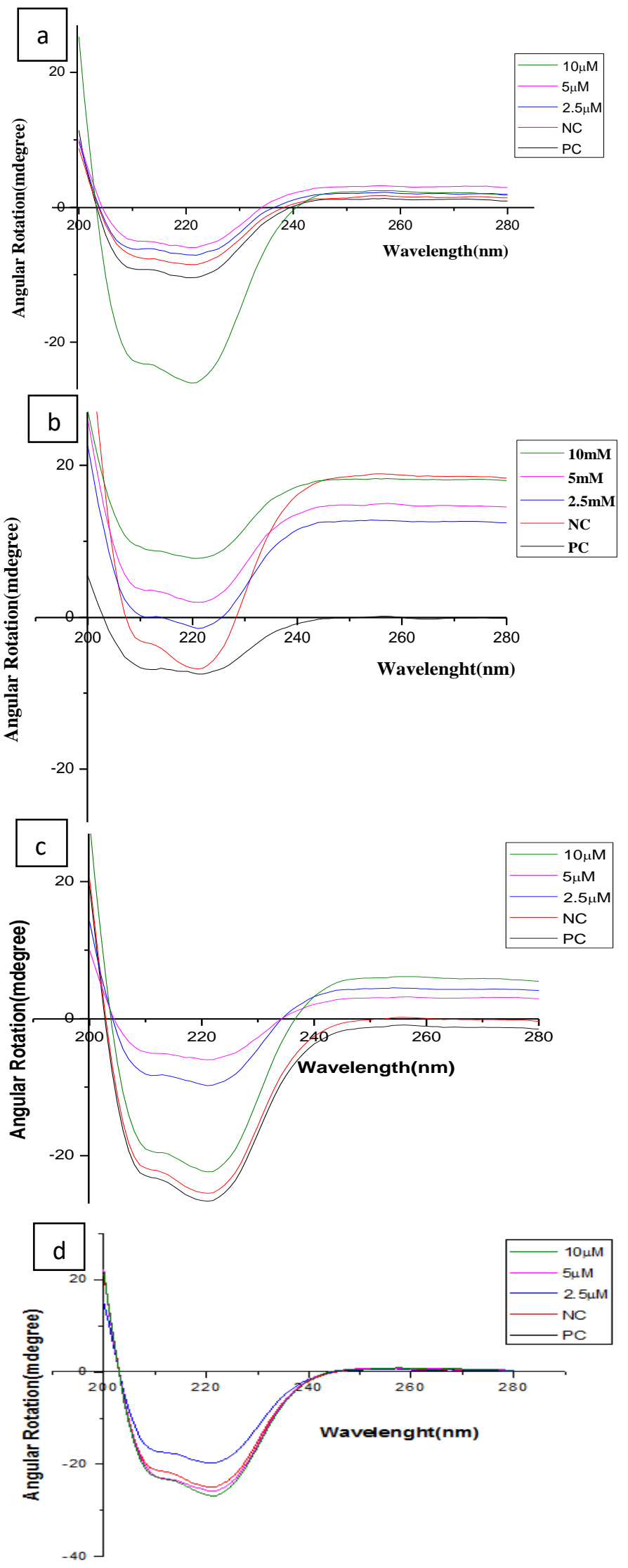



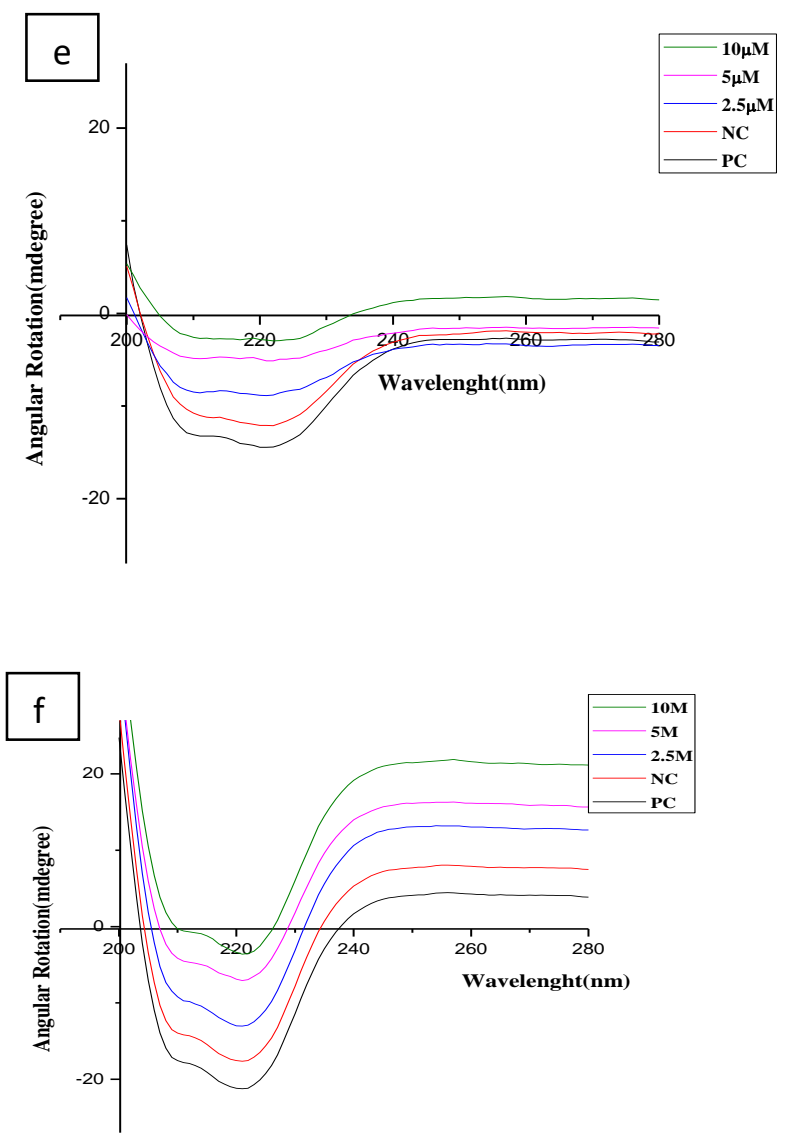

Figure 7

$\mathrm{a}, \mathrm{b}, \mathrm{c}$ : Confirmation of Protein change in RBC after treatment with AflB1 after 3, 6 and 12 hours respectively with CD spectroscopy

d, e, f: Confirmation of Protein change in RBC after treatment with AflG1 after

3,6 and 12 hours respectively with CD spectroscopy

\section{Detection by Power Meter}

Due to the nano dimensions, the fiber has many dangle bonds and it can react with the $\mathrm{OH}^{-}$(hydroxyl ion) and the $\mathrm{H}^{+}$(hydrogen ion) present in the solution.As the interaction of two different molecules leads to the changes of $\mathrm{pH}$ of the solution, thus we took the solution of the treated Hbwith different concentration of AflB1 and AflG1 and used the etched optical nanofiber to detect the changes in $\mathrm{pH}$ of the solutions. By studying the power received from the optical nanofibre we first made a calibration curve by using the solution of the known $\mathrm{pH}$. Now as per the schematic diagram shown in Fig 8, we have measured the $\mathrm{pH}$ of our solutions (containing the cell suspension of RBCs alone and the treated one) and compared their results with the calibrated curve, we can estimate the $\mathrm{pH}$ of the solution of the RBCstreated by the mycotoxins. All the results have shown in table 2. We have calculated the changes of ph of the treated cells with the standard curve shown in the Fig: 9 .

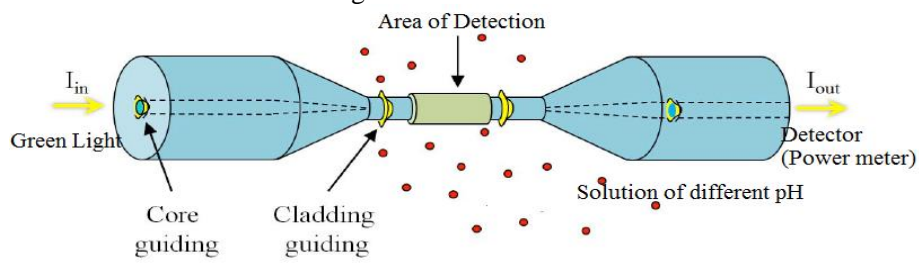

Figure 8 Schematic diagram showing the light detection pathway using optical nano fiber

\section{pH vs Intensity}

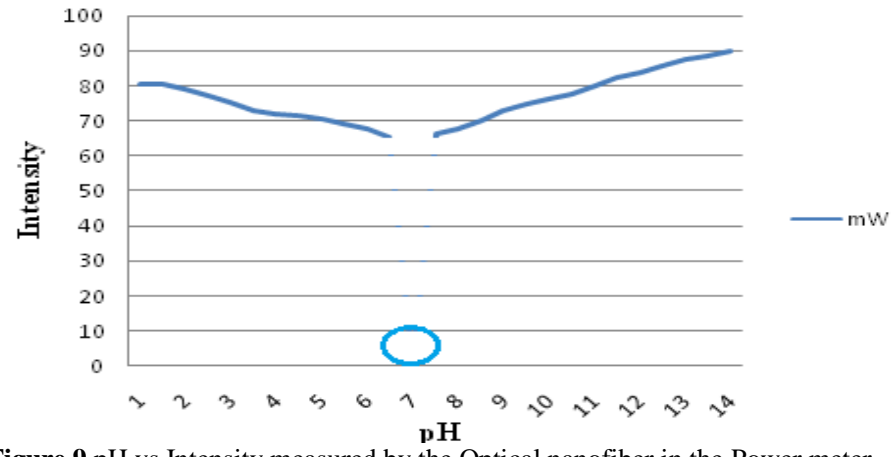

Figure $9 \mathrm{pH}$ vs Intensity measured by the Optical nanofiber in the Power meter

Table 2 Intensity measured by the Optical nanofiber with a Power meter (accuracy: (+)(-) 0.786) (square mean value of triplicate study)

\begin{tabular}{|c|c|c|c|c|c|}
\hline \multirow{2}{*}{$\begin{array}{l}\text { TIME } \\
\text { (HRS) }\end{array}$} & \multirow[t]{2}{*}{ CONCENTRATION } & \multicolumn{2}{|l|}{ AFLB1 } & \multicolumn{2}{|l|}{ AFLG1 } \\
\hline & & $\begin{array}{l}\text { Intensity With Blood } \\
\text { Cells(mW) }\end{array}$ & $\begin{array}{l}\text { Intensity Without } \\
\text { Blood Cells(mW) }\end{array}$ & $\begin{array}{l}\text { Intensity With Blood } \\
\text { Cells(mW) }\end{array}$ & $\begin{array}{l}\text { Intensity } \\
\text { Without Blood } \\
\text { Cells(mW) }\end{array}$ \\
\hline \multirow{3}{*}{3} & $10 \mu \mathrm{M}$ & 75.126 & 85.630 & 70.934 & 79.630 \\
\hline & $5 \mu \mathrm{M}$ & 70.126 & 76.231 & 65.103 & 75.967 \\
\hline & $2.5 \mu \mathrm{M}$ & 61.310 & 70.985 & 60.843 & 71.008 \\
\hline \multirow{3}{*}{6} & $10 \mu \mathrm{M}$ & 71.250 & 82.560 & 70.605 & 79.560 \\
\hline & $5 \mu \mathrm{M}$ & 63.872 & 79.945 & 62.498 & 72.879 \\
\hline & $2.5 \mu \mathrm{M}$ & 51.058 & 77.987 & 51.052 & 67.586 \\
\hline \multirow{3}{*}{12} & $10 \mu \mathrm{M}$ & 58.379 & 80.637 & 55.484 & 70.637 \\
\hline & $5 \mu \mathrm{M}$ & 50.351 & 73.237 & 47.579 & 61.289 \\
\hline & $2.5 \mu \mathrm{M}$ & 48.829 & 62.037 & 41.558 & 54.289 \\
\hline
\end{tabular}

\section{CONCLUSION}

RBC has shown the morphological changes because of the changes in thestructure of the Haemoglobin due to the mycotoxin treatments. The changes of the oxidation state of the AflB1 were seen on a particular time variation. Thus from the experiments, we can conclude that the AflB1 and the AflG1 react with the $\mathrm{Hb}$ and not with the other proteins present in the $\mathrm{Hb}$ and changes of state occurs due to the chemical nature of the Iron present in the Hb. This signifies that the hazards occurred only in $\mathrm{Hb}$ of the RBCs which is more harmful to the living beings. Another serious conclution can be made from the FTIR analysis that determination of the bonding between the drugs and the proteins can be determined by this analysis by calculating the collision energy of an electron which can be derived from the intensity found in the FTIR graph.Though there are many sensors present in the market, the important finding of our workis that the use of optical fiber in nano dimensions is quite fruitful and those are easily available in the market in lower price. These fibers are capable of detecting the minor changes in the $\mathrm{pH}$ of a solution due to the presence of dangle bonds in it and may improve the detection procedure of the affected cell by the changes in $\mathrm{pH}$ of a solution and also the marker proteins present in the cells. The other market procedure for detecting the biochemical changes are the lengthy, costly and time-consuming. Thus this sensor made of the optical fiber is very useful as the light does not interact with the medium and thus it can be used in different medium also.In near future we are planning to work in vivo model and standerize the protocol for the making of optical bio sensor and using this as a powerful sourse to detect abnormalities in the cells and others.

Acknowledgment: We want to acknowledge the Department of Biotechnology (Govt. of India) for the financial support. We would also want to thank Dr. 
Gautam Bose from J.C. Bose Institute and Department of Biotechnology of Jadavpur University for running ofthe different experiments. We like to thank Department of Biotechnology (Government of India) and Centurion University of Technology and Management, Bhubaneswar for funding our work.

\section{REFERENCES}

ABDULKADAR AHW, AL-ALI AA, AL-KILDA AM, AL-JEDAH JH. (2004). Mycotoxins in food products available in Qatar. Food Control 15:543548.https://doi.org/10.1016/j.foodcont.2003.08.008

ACAR J. (1998). Microbiological spoilage in fruits vegetables and their products, and prevention methods. In: Unluturk A, Turantas F, eds. Food Microbiology. 319-360.https://doi.org/10.1007/978-1-4615-2393-2 7

ANGELA LEUNG, P. MOHANA SHANKAR, RAJ MUTHARASAN . A review of fiber-optic biosensors Sensors and Actuators B 125 (2007) 688-703. https://doi.org/10.1016/j.snb.2007.03.010

BHADRA PREETHA, DAS MUKHOPADHYAY CHITRANGADA, AND MUKHERJEE SAMPAD. Determining The Effect Of Aflatoxin B1 Using Hemoglobin Of Human Blood As Interacting Medium By Calculation O Collision Energy.ISSN: 2320-5407. (2017). https://doi.org/10.21474/ijar01/3871 BHATIA V 1999 Applications of long-period gratings to single and multiparameter sensing Opt. Express 4 457-66. https://doi.org/10.1364/oe.4.000457

BHATIA V AND VENGSARKAR A M 1996 Optical fiber long-period grating sensors Opt. Lett. 21 692-4. https://doi.org/10.1364/ofs.1996.we43

BHATTACHARYA, D., BHATTACHARYA, R., DHAR, T. K. (1999). A novel signal amplification technology for ELISA based on catalyzed reporte deposition. Demonstration of its applicability for measuring aflatoxin B1. J. Immunol. Meth. 230:71-86.

BING LI ET AL., Biosens. Bioelectron. 72 (2015) 313. https://doi.org/10.1016/s0022-1759(99)00124-6

BODINE, A.B. AND MERTENS, D.R. 1983.Toxicology, Metabolism and Physiological Effects of Aflatoxin in the Bovine. In Diener, https://doi.org/10.3109/15569548909059745

CAST. 1989. Mycotoxins: Economic and Health Risks. Task Force Report No 116. Aimes, IA: Council for Agricultural Science and Technology.https://doi.org/10.4102/satnt.v5i3.991

CHRIS M. MARAGOS. Emerging Technologies for Mycotoxin Detection. Journal of Toxicology. Toxin Reviews. 2004.https://doi.org/10.1081/txr200027859

C.R. POLLOCK, Fundamentals of Optoelectronics, Irwin, Burr Ridge, IL, 1995.https://doi.org/10.1201/9781420056990.ch3

D. LITTLEJOHN, D. LUCAS, L. HAN. Bent Silica fiber evanescent absorption sensors for near-infrared spectroscopy, Appl. Spectros. 53 (7) (1999) $845-$ 849.https://doi.org/10.1366/0003702991947423

DOWELL, F. E., RAM, M. S., SEITZ, L. M. (1999). Predicting scab, vomitoxin, and ergosterol in single wheat kernels using near-infrared spectroscopy. Cereal Chem. 76:573-576.https://doi.org/10.1094/cchem.1999.76.4.573

DOWELL, F. E., PEARSON, T. C., MAGHIRANG, E. B., XIE, F., WICKLOW, D. T. (2002). Reflectance and transmittance spectroscopy applied to detecting fumonisin in single corn kernels infected with Fusarium verticillioides. Cereal Chem. 79:222-226.https://doi.org/10.1094/cchem.2002.79.2.222

GARDEN, S. R., STRACHAN, N. J. C. (2001). Novel colorimetric immunoassay for the detection of aflatoxin B1. Anal. Chim. Acta 444:187191.https://doi.org/10.1016/s0003-2670(01)01231-4

GENDLOFF E.H., E.C. ROSSMAN, W.L. et.al, 1986 Components of resistance to Fusarium ear rot in field corn. Phytopathol. 76: 684688.https://doi.org/10.1094/phyto-76-684

HANSON MS, STEPHENSON AH, BOWLES EA etal. Phosphodiesterase 3 is present in rabbit and human erythrocytes and its inhibition potentiates iloprostinduced increases in cAMP. Am.J.Physiol Heart Circ.Physiol 2008;295: H786H793. https://doi.org/10.1152/ajpheart.00349.2008

HIRANO, S., OKAWARA, N., NARAZAKI, S. (1998). Near infra red detection of internally moldy nuts. Biosci. Biotechnol. Biochem. 62:102107.https://doi.org/10.1271/bbb.62.102

HOLLAN, S.: Membrane fluidity of blood cells. Haematologica (Budapest), 1996, 27, 109-127.https://doi.org/10.1016/b978-0-12-053003-8.50008-9

JEON, D.Y., PARK, S.J., MOUIS, M., BARRAUD, S., KIM, et.al: Lowtemperature electrical characterization of junctionless transistors. Solid State Electron. 80, 135-141 (2013).https://doi.org/10.1016/j.sse.2012.10.018

J. BURES AND R. GHOSH, "Power density of the evanescent field in the vicinity of a tapered fiber," Journal of the Optical Society America A, vol. 16, no.8, pp. 1992-1996, 1999.https://doi.org/10.1364/josaa.16.001992

J. Y. LOU, L. M. TONG, AND Z. Z. YE, "Modeling of silica nanowires for optical sensing," Optics Express, vol. 13, no. 6, pp. 2135-2140, 2005.https://doi.org/10.1364/opex.13.002135

KATONA, E., KATONA, G. et al.: Drug-Induced Membrane Effects in Metabolically Impaired and Nonimpaired Human T (Jurkat) Lymphoblastoid Cells. Romanian J. Biophys., 2004, 14, 29-36.https://doi.org/10.1016/0198$\underline{8859(81) 90085-9}$
K. CHAROENPORNSOOK AND P. KAVISARASAI. Mycotoxins In Animal Feed Stuffs of Thailand.KMITL Sci. Tech. J. 2006.https://doi.org/10.1533/9781855739086.2.262

KERSEY A D, Davis M A, Patrick H J, et al., 1997 Fiber grating sensors J. Lightwave Technol. 15 1442-63 .https://doi.org/10.2174/978160805084011101010171

KOE, W. J., SAMSON, R. A., VAN EGMOND, H. P., et al., Mycotoxins and Phycotoxins in Perspective at the Turn of the Millennium. 1st ed. Wageningen: Ponsen\&Looyen, pp. 29-40.https://doi.org/10.1515/ci.2002.24.1.23b

KOS, G., LOHNINGER, H., KRSKA, R. (2002). Fourier transform mid-infrared spectroscopy with attenuated total reflection (FT-IR/ATR) as a tool for the detection of Fusarium fungi on maize. Vib. Spec. 29:115119.https://doi.org/10.1255/jnirs.290

LAKOWICZ, J. R.: Principles of Fluorescence Spectroscopy, 2nd edition, Springer Science and BusinessMedia Inc., 2004, pp. 298299.https://doi.org/10.1002/9780470692059.ch7

L. M. TONG, J. Y. LOU, AND E. MAZUR, "Single-mode guiding properties of sub wavelength-diameter silica and silicon wire waveguides," Optics Express, vol. 12, no. 6, pp. 1025-1035, 2004.https://doi.org/10.1002/9780470692059.ch7 L. M. TONG, R. R. GATTASS, J. B. ASHCOMet al. "Subwavelength-diameter silica wires for low-loss optical wave guiding," Nature, vol. 426, no. 6968, pp 816-819, 2003.https://doi.org/10.1038/nature02193

LEI ZHANG, JINGYI LOU, AND LIMIN TONG.Micro/Nanofiber Optical Sensors. Photonic Sensors (2011) Vol. 1, No. 1: 31-42. https://doi.org/10.1007/s13320-010-0022-z

MARAGOS, C. M. (1997). Detection of the mycotoxin fumonisin B1 by a combination of immunofluorescence and capillary electrophoresis. Food Agric. Immunol. 9:147-157.https://doi.org/10.1080/09540109709354945

MARAGOS, C. M., THOMPSON, V. S. (1999). Fiber-optic immunosensor for mycotoxins. Nat. Toxins 7:371-376.https://doi.org/10.1002/1522 7189(199911/12)7:6<371::aid-nt86>3.0.co;2-8

MELDA SONMEZ, HUSEYINYAVUZ INCE, OZLEM YALCIN et al., The Effect of Alcohols on Red Blood Cell Mechanical Properties and Membrane Fluidity Depends on Their Molecular Size. PLOS ONE. September 2013.https://doi.org/10.1371/journal.pone.0076579

MIRGHANIA, Y.B. CHEMANA, S. JINAPB, B.S. BAHARINA, AND J. BAKARA.A New Method for Determining Aflatoxins in Groundnut and Groundnut Cake Using Fourier Transform Infrared Spectroscopy with Attenuated Total Reflectance. M.E.S. JAOCS, Vol. 78, no. 10 (2001).https://doi.org/10.1007/s11746-001-0376-y

NAYAK, K., BAJAJ, M., KONAR, A., OLDIGES, P.J., et al., CMOS logic device and circuit performance of $\mathrm{Si}$ gate all around nanowire MOSFET. IEEE

Trans. Electron Devices 61(9), 3066-3074 (2014). https://doi.org/10.1109/ted.2014.2335192

O. S. WOLFBEIS, "Fiber-Optic Chemical Sensors and Biosensors," Analytical Chemistry, vol. 80, no. 12, pp. 4269-4283, 2008.https://doi.org/10.1007/978-3642-02827-4 5

PEARSON, T. (1996). Machine vision system for automated detection of stained pistachio nuts. Lebensmitelw. U. Technol. 29:203209.https://doi.org/10.1006/fstl.1996.0030

PEARSON, T., WICKLOW, D. T., MAGHIRANG, E. et al., (2001). Detecting aflatoxin in single corn kernels by transmittance and reflectance spectroscopy. Trans. ASAE 44:1247-1254. 4. https://doi.org/10.13031/2013.6418

RUAN, R., NING, S., SONG, A., et al., (1998). Estimation of Fusarium scab in wheat using machine vision and a neural network. Cereal Chem. 75:455459.https://doi.org/10.1094/cchem.1998.75.4.455

S.K. KHIJWANIA, B.D. GUPTA, Fiber optic evanescent field absorption sensor: effect of fiber parameters and geometry of the probe, Opt. Quant. Electron. 31 (8) (1999) 625-636.https://doi.org/10.1364/ofs.1996.th33

SHARMA, R.P. 1985Immunotoxicology of Food Constituents, Food Technology, 39, 94.https://doi.org/10.1007/978-3-642-54596-2 200584

SHARMA, R.P. 1993Immunotoxicity of Mycotoxins, Journal of Dairy Science, 76, 892-897.https://doi.org/10.3168/jds.s0022-0302(93)77415-9

SMITH, J.E. AND HENDERSON, R.S. 1991 Mycotoxins and Animal Foods Boca Raton, F.L: CRC Press Inc.https://doi.org/10.3920/978-90-8686-877-3 10 SHEPHARD, G. S. (2001). Analytical methodology for mycotoxins: recent advances and

challenges.https://doi.org/10.2520/myco1975.2003.suppl3 215

SHRIVASTAVA, S., CHATTOPADHYAY, A.: Influence of cholesterol and ergosterol on membrane dynamics using different fluorescent reporter probes. Biochem. Biophys. Res. Commun., 2007, 356, 70510.https://doi.org/10.1016/j.bbrc.2007.03.032

STEPHEN W JAMES AND RALPH P TATAM. Optical fiber long-period grating sensors: characteristics and application. Meas. Sci. Technol. 14 (2003) R49-R61 PII: S0957-0233(03)55184-0. https://doi.org/10.1117/12.2302080

SYDENHAM, E. W., SHEPHARD, G. S. (1997). Chromatographic and allied methods of analysis for selected mycotoxins. In: Gilbert, J., ed. Progress in Food Contaminant Analysis. New York: Chapman and Hall, pp. 65146.https://doi.org/10.1007/978-1-4613-1117-1 3 
TRUCKSESS, M. W. (2001). Rapid analysis (thin layer chromatographic and immunochemical methods) for mycotoxins in foods and feeds. https://doi.org/10.1016/s0308-8146(98)00113-7

U.L., ASQUITH, R.L. AND DICKENS, J.W. EDS. Aflatoxin and Aspergillus flavus in Corn. Alabama, Alabama Ag. Exp. Sta.,Auburn University, 279: 4650.https://doi.org/10.1094/phyto-66-675

WANG, T., LOU, L., LEE, C.: A junctionless gate-all-around silicon nanowire FET of high linearity and its potential applications. IEEE Electron Devices Lett. 34(4), 478-480 (2013). https://doi.org/10.1109/led.2013.2244056

WILLIUM PEVELER, AND ALGAR. More Than a Light Switch: Engineering

Unconventional Fluorescent Configurations for Biological Sensing. ACS

Chemical Biology. $201813(7), \quad$ pp 1752-1766. (2018).

https://doi.org/10.1021/acschembio.7b01022 